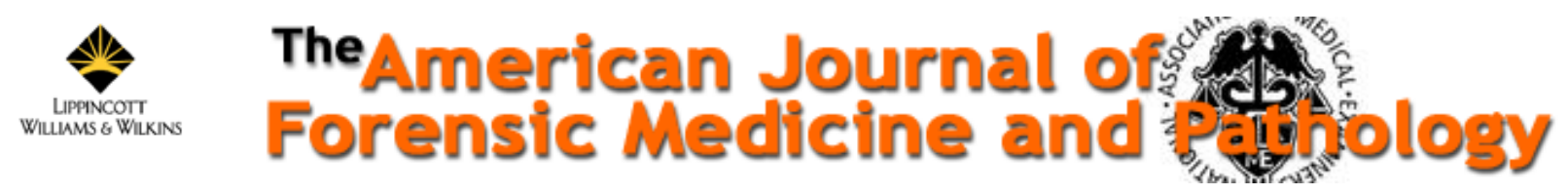

The American Journal of Forensic Medicine and Pathology: Volume 19(3) September 1998 pp 201-205

\title{
Reexamination of Custody Restraint Position and Positional Asphyxia
}

Chan, Theodore C. M.D.; Vilke, Gary M. M.D.; Neuman, Tom M.D.

From the Department of Emergency Medicine, University of California San Diego Medical Center, San

Diego, California, U.S.A.

Received June 20, 1997; accepted June 25, 1997.

Address correspondence and reprint requests to Theodore Chan, University of California San Diego

Medical Center, 200 West Arbor Drive \#8676, San Diego, CA 92103, U.S.A.

\begin{abstract}
The use of the hogtie restraint (also known as hobble or prone maximal restraint) by law enforcement and prehospital personnel has come under scrutiny because of reports of sudden deaths in persons placed in this restraint position. Some contend that this body position restricts chest and abdominal movement to the point that individuals are at risk for hypoventilatory respiratory compromise and "positional" asphyxiation. We review case reports of custody deaths in subjects placed in the hogtie position, as well as related medical literature regarding positional asphyxia. We also review the current research findings from human physiology studies that have investigated the effects of the hogtie position on respiratory and pulmonary function. We conclude that the hogtie restraint position by itself does not cause respiratory compromise to the point of asphyxiation and that other factors are responsible for the sudden deaths of individuals placed in this position.
\end{abstract}

Physical restraints are commonly used by law enforcement and prehospital medical personnel to subdue violent, combative individuals. Certain methods and techniques of physical restraint have been found to be potentially harmful to individuals. For example, the use of neck "choke holds" has been banned by most law enforcement agencies as a result of studies documenting the risks and dangers of this restraint technique $(1,2)$.

The "hogtie" or "hobble" custody restraint position has come under scrutiny because of reports of sudden deaths of persons placed in this restraint position. In the hogtie position, subjects are placed in the prone position with wrists and ankles bound behind the back and secured together by means of a cord or "hobbling" device. Investigators have proposed that this position impairs normal respiratory function and places individuals at risk for asphyxiation from body position or "positional asphyxia."

Normal respiration depends on three critical components: a patent airway; the lungs, where gas exchange occurs; and a ventilatory apparatus or bellows that moves gases between the external environment and the lungs. Ventilation depends on the movement of the chest wall, rib cage, diaphragm, abdominal wall, and other accessory muscles of 
respiration to generate intrathoracic pressures that move gases through the airway to and from the lungs $(3,4)$.

Respiratory failure occurs when one of these three components fails. Lung disease leads to gas exchange abnormalities and increased alveolar-arterial oxygen gradient, manifested by decreases in oxygenation and resultant hypoxemia. Ventilatory bellows failure leads to alveolar hypoventilation and retention of carbon dioxide, manifested primarily by hypercapnia. The three major causes of ventilatory pump failure are decreased central respiratory drive, such as with barbiturate over-doses, chest wall mechanical defects, such as with flail chest injuries, and respiratory muscle fatigue and failure (3-5).

The term positional(also "postural") asphyxia has been used to describe the deaths of individuals who were reportedly found in body positions that interfered with normal breathing. In these cases, investigators found the deceased in a position that resulted in failure to maintain a patent airway or failure to maintain adequate ventilatory function. In addition to the actual body position, other criteria suggesting the diagnosis of positional asphyxia have been proposed: (a) evidence that circumstances prevented the individual from escaping the fatal body position; (b) historical information indicating that the individual had "difficulty in breathing"; and (c) absence of other pathologic or toxicologic findings clearly suggesting another cause of death(6).

Bell et al. reviewed 30 cases of positional asphyxiation occurring during a 9-year period. In all cases, victims had no other significant life-ending pathologic findings. Most commonly, victims were found in positions that resulted in upper airway obstruction, including head-neck hyperflexion and lying face down on a suffocating object. Acute alcohol intoxication was a major risk factor for asphyxiation and explained why many of these individuals were unable to alter the body position that led to positional asphyxiation (7). A similar asphyxiation phenomenon, termed "mechanical asphyxia," has been described with the use of vest, jacket, and chest posey restraints, particularly in the geriatric nursing home population. Asphyxiation occurs when these restraints accidentally wrap around the necks of individuals and result in strangulation (8-11).

Although most of these cases involved airway obstruction, reports exist of asphyxiation from ventilatory bellows failure. In their review, Bell et al. reported on four victims found in confined positions that restricted chest and diaphragmatic movement and thus may have resulted in hypoventilatory respiratory failure (7). In addition to the reports of strangulation from vest, jacket, and posey chest restraints are reports of ventilatory compromise and asphyxiation from these devices. In these cases, subjects became suspended from a bed or chair by their restraints, with resulting chest constriction to the point of mechanical ventilatory impairment $(12,13)$.

Similarly, investigators have suggested that the hogtie restraint position places subjects at risk for asphyxiation from their body position. Numerous case reports in the medical literature describe deaths occurring in individuals placed in this restraint position while in 
law enforcement custody. In many of these cases, the deaths have been attributed to positional asphyxia (6,14-17).

\section{CASE REPORTS}

In 1985, Wetli and Fishbain reported 7 cases of death in cocaine users. In their report, they noted that 5 individuals were in police custody at the time, and 4 were placed in a hogtie-like restraint position. The authors attributed these deaths to cocaine intoxication, possibly complicated by other factors including "restraint stress" (18).

In 1992, Reay et al. first reported 3 cases of positional asphyxia occurring in individuals placed in the prone restraint position in the back seat of police patrol cars. In all cases, the subjects were violent and agitated, either from drug and alcohol intoxication or from psychiatric illness, and required multiple law enforcement officers to subdue them. During transport, the subjects became unresponsive and were subsequently found in cardiopulmonary arrest. On autopsy, no clear lethal anatomic or toxicologic findings were noted, and, as a result, all the deaths were attributed to positional asphyxia. Reay et al. assert that the deaths were the result of adverse physiologic effects created by the semiprone and hogtie positions in a confined space (6).

In 1993, O'Halloran and Lewman reported 11 cases of sudden death occurring in subjects placed in the prone position, 9 of whom were in the hogtie restraint position. All the subjects were combative, violent, and in an "excited delirious state" as a result of acute psychosis or drug intoxication (most commonly cocaine). Violent confrontation and struggle occurred in all cases. Two of these individuals were subjected to stun gun shocks shortly before death. Although the authors admit drug intoxication could cause death without positional asphyxiation from restraint position, nevertheless they assert that the position "clearly impairs breathing in situations of high oxygen demand by inhibiting chest wall and diaphragmatic movement" (14).

In 1995, Stratton et al. were the first to report 2 cases of unexpected deaths in individuals who were placed in the restraint position and subsequently died while being transported by prehospital medical personnel. Both cases involved men who were agitated, combative, and under the influence of illegal drugs. The authors proposed that the restraint position leads to "restriction of motion of the diaphragm and chest" and that such positioning "can lead to asphyxia" (15).

In 1996, Ross reviewed 22 cases of sudden death in the prone or hogtie position reported in the medical literature from 1988 through 1993. Of these, 18 occurred in individuals in the hogtie restraint position, 2 were restrained prone on gurneys, and 2 were manually restrained in a prone position. All exhibited violent, combative behavior and fought or struggled with the police. Drug use and alcohol intoxication were noted in 16 cases. Cocaine use was noted in 12 subjects. Positional asphyxia was listed as the sole cause of death in 5 cases and as a contributing cause of death along with drug intoxication in another 6 cases. The author concluded that placing a subject in a"confining position which restricts the natural respiration process" can be fatal, and that "based on the risk of 
sudden death, the practice of hogtying and transporting subjects in a prone position should be discontinued" (16).

In 1992, the San Diego Police Department in conjunction with the County Medical Examiner's Office formed a Custody Death Task Force to examine the issues surrounding in-custody deaths. Spurred by 7 cases of in-custody death in San Diego, 3 of which occurred in individuals placed in the hogtie restraint position, the Task Force conducted a national survey of law enforcement agencies, 39\% of which reported experiencing incustody deaths. The task force was able to confirm 94 cases of restraint-associated incustody deaths across the country during the previous decade, though the actual number of deaths was likely higher because of incomplete or insufficient data collection. Fortythree agencies or $30 \%$ of those responding at that time authorized the use of the hogtie restraint position by their officers in subduing violent individuals. The number of hogtie custody restraint fatalities was not determined (17).

\section{POSITIONAL ASPHYXIA}

Although deaths clearly have occurred in individuals placed in the restraint position, the role of actual body position and of positional asphyxia in these situations is unclear. As noted in the case report literature, investigators have postulated that the restraint position prevents adequate chest wall, abdominal, and diaphragmatic movement for normal ventilatory function and breathing. This inability to expand the thoracic cavity and the resultant disadvantage in pulmonary mechanics lead to hypoventilatory respiratory failure, asphyxiation, and death. Hirsh argued that the evidence suggesting "postural compromise of ventilation and respiration" is sufficient and that it is "prudent and appropriate for medicolegal officials to consistently classify as homicide the type of deaths" associated with custody restraint positions (19).

Yet, no clear data support many of the conclusions drawn in the case report literature regarding positional asphyxia and the hogtie restraint position. Many have argued that factors unrelated to the restraint position may play a greater role in causing these deaths. Most reported cases involve young men in an "excited" state or one of "agitated delirium" as a result of psychiatric illness or intoxication from illegal drugs. These individuals were combative, violent, and often struggled or suffered traumatic injuries as a result of confrontation with law enforcement before their placement in the restraint position.

Investigators have argued that these other factors, such as delirium, intoxication, stress, trauma, catecholamine hyperstimulation, hyperthermia, muscle fatigue, and exhaustion, as opposed to asphyxiation from body positioning, are more important in explaining the deaths of these individuals (20-22). Laposata suggested that the evidence to cite positional asphyxia alone as a cause of death is insufficient, and the position "is not in itself a position that would be expected to be fatal within minutes," as has been reported in many cases (20).

In addition, the level of chest and abdominal constriction that may result in significant ventilatory or respiratory dysfunction is unclear. Ward and Macklem suggested that, 
although significant chest restriction may impede ventilation, restriction of abdominal motion should not influence ventilatory bellows function because diaphragmatic movement may in fact occur at a more efficient length (4).

\section{PHYSIOLOGIC STUDIES}

Where then is the scientific data supporting the occurrence of positional asphyxia in individuals placed in the hogtie restraint position? The theory of positional asphyxia is based primarily on the work of Reay et al. (23). Reay studied 10 healthy individuals who were placed in the hogtie restraint position after a period of exercise on a stationary cross-country ski machine to a maximum heart rate of 120 beats per minute. These authors found statistically significant physiologic differences in the subjects in the restraint position versus those in a sitting position after exercise. Overall, subjects in the restraint position had prolonged recovery times after exercise for both heart rate (mean duration of recovery 0.40 minutes longer in the restraint position) and peripheral oxygen saturation measured by transcutaneous ear probe (mean duration of recovery 0.33 minutes longer). Based on these findings, Reay et al. postulated that deaths occurring in individuals in the hogtie restraint position were the result of adverse physiologic and respiratory effects from body position. They further argued that the prone restraint position restricts chest and abdominal movement and thereby reduces respiratory tidal volumes, placing an individual at risk for hypoventilation, hypercapnia, hypoxemia, and asphyxiation(6,23).

Several points must be considered when evaluating this work. First, oxygenation in the experimental subjects was measured by transcutaneous pulse oximetry. This method has been shown to be a potentially inaccurate measure of arterial oxygenation, particularly during exercise. The preferred method for assessing arterial blood oxygenation remains arterial blood gas measurements, which are more accurate and reliable (24-26).

Reay et al. also reported decreases in oxygen saturation to $85 \%$ to $90 \%$ with exercise in his healthy subjects. This finding is surprising because mild-to-moderate levels of exercise improves ventilation-perfusion ratios throughout the lung zones, decreases the arterial-alveolar gas exchange gradient, and improves pulmonary blood flow. Moreover, minute ventilation increases with exercise and results in lower arterial Pco2 levels (27). Accordingly, in contrast to Reay's findings, previous well-established work in exercise physiology has demonstrated that arterial oxygenation improves, rather than decreases, with exercise in healthy individuals $(27,28)$.

Second, although heart rate and pulse oximetry were monitored in these subjects, no direct measure of ventilatory function was performed. Ventilatory function while in the restraint position is crucial to the theory of positional asphyxia, because investigators have postulated that the position prevents adequate chest and abdominal diaphragmatic movement to the point of hypoventilatory respiratory failure.

Schmidt et al. completed a study similar to that of Reay et al., with significantly different results(29). Schmidt studied 18 healthy subjects, monitoring heart rate and oxygen 
saturation by pulse oximetry after exercise (stationary bicycle to a heart rate of 120 beats per minute) in the sitting versus restraint position. Unlike Reay et al., Schmidt et al. found no difference in mean heart rate and no evidence of oxygen desaturation in either position after exercise. Schmidt et al. further monitored subjects after a more vigorous simulated pursuit and physical struggle regimen. Again, no physiologic differences were found in either position (29).

Another recent study further examined the respiratory and physiologic effects of the hogtie restraint position (30). Fifteen healthy volunteers underwent a 2-phase crossover controlled trial. In phase 1, subjects underwent pulmonary function testing (PFT) in four different body positions: sitting, supine, prone, and restraint(hogtie position). In the second phase, subjects underwent a 4-minute exercise period followed by a 15-minute period in either the sitting or the restraint position. During the postexercise period, serial arterial blood gas measurements were obtained, subjects underwent electrocardiographic and pulse oximetry monitoring, and PFTs were performed.

A progressive restrictive pattern of PFTs was observed as subjects were in the sitting to supine to prone to restraint positions. Mean forced vital capacities fell with each position compared to sitting (declines of 7\%, 7\%, and 13\% of predicted values for the supine, prone, and restraint positions, respectively). Mean forced expiratory volumes in 1 second fell in a similar fashion (declines of $8 \%, 9 \%, 14 \%$ of predicted values, respectively), as did maximal voluntary ventilation (declines of $10 \%, 15 \%$, and $23 \%$ of predicted values, respectively). Exercise itself resulted in no further restrictive impairment in PFTs (30).

These findings in isolation appear to support the theory of positional asphyxia from the restraint position. However, PFT measurements as low as $80 \%$ of predicted values are still normal, and these changes, although statistically significant, are of little clinical relevance(31). Furthermore, PFT changes consistent with a restrictive pattern were also seen simply by placing subjects in a supine or prone position. If one were to argue that certain individuals may be at greater risk of hypoventilation in the restraint position, then one would also have to conclude that these individuals were at risk even in the supine or prone position.

Most important, no evidence of respiratory compromise was noted during either the exercise or the postexercise period in the restraint position. Based both on serial arterial Po2 and co-oximetry monitoring, oxygenation increased rather than decreased with exercise (30). This improvement in oxygenation occurred in the face of vigorous exercise to a mean heart rate of 169 beats per minute. These findings are consistent with previous studies in exercise physiology $(27,28)$.

Moreover, despite the PFT findings, no evidence of hypoxia, hypercapnia, or delay in heart rate recovery was noted while subjects were in the restraint position after exercise. In fact, mean Pco2 levels decreased during exercise and remained lower than $40 \mathrm{~mm} \mathrm{Hg}$ for as long as 15 minutes after exercise while subjects were in the restraint position(30). These findings demonstrated that, despite the restrictive PFT pattern, no evidence 
indicated hypoventilation or ventilatory compromise as a result of body positioning in the restraint position.

\section{CONCLUSIONS}

Based on these findings, factors other than body positioning appear to be more important determinants for sudden, unexpected deaths in individuals in the hogtie custody restraint position. Illicit drug use (including sympathomimetic, hallucinogenic, and psychomotor stimulant drugs), physiologic stress, hyperactivity, hyperthermia, catechol hyperstimulation, and trauma from struggle may be more important factors in the deaths of these individuals. Although restraints in general increase the psychological and physiologic stress on the individual, no evidence suggests that body position alone causes hypoventilation, respiratory compromise, or positional asphyxia in the hogtie custody restraint position.

\section{REFERENCES}

1. Reay DT, Eisele JW. Deaths from law enforcement neck holds. Am J Forensic Med Pathol 1982;3:253.

[Medline Link] [Context Link]

2. Reay DT, Holloway GA. Changes in carotid blood flow produced by neck compression. Am J Forensic Med Pathol 1982;3:199.

[Medline Link] [Context Link]

3. Roussos C, Macklem PT. The respiratory muscles. N Engl J Med 1982;307:786.

[Medline Link] [Context Link]

4. Ward M, Macklem PT. The act of breathing and how it fails. Chest 1990;97:36S.

[Medline Link] [Context Link]

5. Roussos C. Respiratory muscle fatigue and ventilatory failure. Chest 1990;97:89S.

[Medline Link] [Context Link]

6. Reay DT, Fligner CL, Stilwell AD, Arnold J. Positional asphyxia during law enforcement transport. Am J Forensic Med Pathol 1992;13:90.

[Medline Link] [Context Link]

7.Bell MD, Rao VJ, Wetli CV, Rodriguez RN. Positional asphyxiation in adults: a series of 30 cases from the Dade and Broward county Florida medical examiner offices from 1982-1990. Am J Forensic Med Pathol 1992;13:101.

[Medline Link] [Context Link]

8.Dube AH, Mitchell EK. Accidental strangulation from vest restraints. JAMA 1986;256:2725.

[Medline Link] [CrossRef] [Context Link]

9. Katz L. Accidental strangulation from vest restraints. JAMA 1987;257:2032.

[Medline Link] [CrossRef] [Context Link]

10. DiMaio VJM, Dana SE, Bux RC. Deaths caused by restraint vests. JAMA 1986;256:905.

[Context Link]

11. Miles S. A case of death by physical restraint: new lessons from a photograph. J Am Geriatr Soc 1996;44:291.

[Fulltext Link] [Medline Link] [Context Link]

12.Miles HS, Irvine P. Deaths caused by physical restraints. Gerontologist 1992;32:762.

[Medline Link] [Context Link]

13. Emson HE. Death in a restraint jacket from mechanical asphyxia. Can Med Assoc J 1994;151:985. [Medline Link] [Context Link]

14. O'Halloran RL, Lewman LV. Restraint asphyxiation in excited delirium.Am J Forensic Med Pathol 1993;14:289.

[Medline Link] [Context Link]

15. Stratton SJ, Rogers C, Green K. Sudden death in individuals in hobble restraints during paramedic transport. Ann Emerg Med 1995;25:710.

[Context Link]

16. Ross DL. An analysis of in-custody deaths and positional asphyxiation. Police Marksman 1996;March/April:16.

[Context Link] 
17. Burgreen B, Krosch C, Binkerd V, Blackbourne B. Final report of the custody death task force. San Diego: San Diego Police Department, 1992.

[Context Link]

18. Wetli CV, Fishbain DA. Cocaine-induced psychosis and sudden death in recreational cocaine users. J Forensic Sci 1985;30:873.

[Context Link]

19. Hirsh CS. Restraint asphyxiation [letter]. Am J Forensic Med Pathol 1994;15:266.

[Medline Link] [Context Link]

20. Laposata EA. Positional asphyxia during law enforcement transport [letter]. Am J Forensic Med Pathol 1993;14:86.

[Medline Link] [Context Link]

21. Karch SB. Agitated delirium versus positional asphyxia. Ann Emerg Med 1995;26:760.

[Medline Link] [Context Link]

22. Mirchandani HG, Rorke LB, Sekula-Perlman A, Hood IC. Cocaine-induced agitated delirium, forceful struggle, and minor head injury. Am J Forensic Med Pathol 1994;15:95.

[Medline Link] [Context Link]

23. Reay DT, Howard JD, Fligner CL, Ward RJ. Effects of positional restraint on oxygen saturation and heart rate following exercise. Am J Forensic Med Pathol 1988;9:16.

[Medline Link] [Context Link]

24. Biebuyck JF. Pulse oximetry.Anesthesiology 1989;70:98.

[Context Link]

25. Norton LH, Squires B, Craig NP, et al. Accuracy of pulse oximetry during exercise stress testing.Int J Sports Med 1992;13:523.

[Medline Link] [Context Link]

26. Hansen JE, Casaburi R. Validity of ear oximetry in clinical exercise testing. Chest 1987;91:333.

[Medline Link] [Context Link]

27. Levitzky MG. Pulmonary physiology, 4th ed. New York: McGraw-Hill, Inc, 1995.

[Context Link]

28. Wasserman K, Hansen JE, Sue DY, Whipp BJ, Casaburi R. Normal values. In: Wasserman K, Hansen JE, Sue DY, Whipp BJ, Casaburi R, eds. Principles of exercise testing and interpretation, 2nd ed. Philadelphia: Lea \& Febiger, 1994:127.

[Context Link]

29. Schmidt MA, Snowden T, Clin J. The effects on oxygen saturation and heart rate of persons due to positional restraint [unpublished report]. San Diego: San Diego Regional Public Safety Training Institute, 1996.

[Context Link]

30. Chan TC, Vilke GM, Neuman T, Clausen JL. Restraint position and positional asphyxia. Ann Emerg Med 1997;30:578.

[Context Link]

31.Clausen JL. Pulmonary function testing. In: Bordow RA, Moser KM, eds. Manual of clinical problems in pulmonary medicine, 4th ed. Boston: Little, Brown, 1996:9.

[Context Link]

\section{Keywords:}

Physical restraint; Hogtie; Positional asphyxia; Law enforcement; Review

(c) 1998 Lippincott Williams \& Wilkins, Inc. 